\title{
The Effects of Pulsed Current Parameters on Porosity of Copper Prepared by Jet Electrodeposition
}

\author{
Hui Fan ${ }^{1,2, *}$, Zhijing Li ${ }^{1}$, Yangpei Zhao ${ }^{3}$, Shankui Wang ${ }^{1}$, Sainan Cao ${ }^{2}$ \\ ${ }^{1}$ kewen college, School of Mechanical and Electrical Engineering, Jiangsu Normal University, \\ Xuzhou, 221116, China \\ 2 Jiangsu Key Laboratory of 3D Printing Equipment and Application Technology, Nantong Institute of \\ Technology, Nantong, 226002, China; \\ ${ }^{3}$ Science department, Jiang su Jiangzhu Institute, Xuzhou, 221116, China \\ "E-mail: xzfanhui@163.com
}

doi: $10.20964 / 2019.04 .48$

Received: 12 January 2019 / Accepted: 12 February 2019 / Published: 10 March 2019

\begin{abstract}
Surface texturing has become an increasingly prevalent approach to improve the tribological properties of materials. The present work aims to study a novel texturing technology. A copper coating with a porous surface structure was directly prepared on stainless steel using a copper sulfate solution bath via high-speed jet electrodeposition. A fine, uniform honeycomb structure with micron sized pores can be achieved using a pulsed current. The duty cycle, current density and current frequency of the pulsed current have a notable influence on the microstructure of the deposited surface. Decreasing the duty cycle and increasing the current density can help to achieve a homogeneous and fine porous surface. The mechanism for depositing a porous surface was discussed according to the roles of the current parameters in the formation of the coating microstructure.
\end{abstract}

Keywords: jet electrodeposition; porous structure; pulse current;

\section{$\underline{\text { FULL TEXT }}$}

(C) 2019 The Authors. Published by ESG (www.electrochemsci.org). This article is an open access article distributed under the terms and conditions of the Creative Commons Attribution license (http://creativecommons.org/licenses/by/4.0/). 